Canadian Journal of Fisheries and Aquatic Sciences

Canadian Science Publishing Journal canadien des sciences halieutiques et aquatiques

\title{
Phenology of Hatching, Emergence, and End-of-Season Body Size in Young-of-Year Coho Salmon in Thermally Contrasting Streams Draining the Copper River Delta, Alaska
}

\begin{tabular}{|r|l|}
\hline Journal: & Canadian Journal of Fisheries and Aquatic Sciences \\
\hline Manuscript ID & cjfas-2018-0003.R2 \\
\hline Manuscript Type: & Article \\
\hline Date Submitted by the Author: & 09-Apr-2018 \\
\hline Complete List of Authors: & $\begin{array}{l}\text { Campbell, Emily; Oregon State University, Fisheries and Wildlife } \\
\text { Dunham, Jason; U.S. Geological Survey } \\
\text { Reeves, Gordon; USDA Forest Service } \\
\text { Wondzell, Steve; U.S. Forest Service, Pacific Northwest Research Station, } \\
\text { Corvallis Forestry Sciences Lab }\end{array}$ \\
\hline $\begin{array}{r}\text { Is the invited manuscript for } \\
\text { consideration in a Special } \\
\text { Issue? : }\end{array}$ & N/A \\
\hline Keyword: & phenology, SALMON < Organisms, life cycle, TEMPERATURE < General \\
\hline \multicolumn{2}{|c}{} \\
\hline
\end{tabular}

\section{SCHOLARONE" \\ Manuscripts}


Phenology of Hatching, Emergence, and End-of-Season Body Size in Youngof-Year Coho Salmon in Thermally Contrasting Streams Draining the Copper River Delta, Alaska

Emily Y. Campbell ${ }^{1}$, Jason B. Dunham ${ }^{2}$, Gordon H. Reeves ${ }^{3}$ and Steve M. Wondzell ${ }^{3}$

${ }^{1}$ Department of Fisheries and Wildlife, Oregon State University, Corvallis, Oregon; embug50@gmail.com

${ }^{2}$ U.S. Geological Survey, Forest and Rangeland Ecosystem Science Center, Corvallis, Oregon; jdunham@usgs.gov

${ }^{3}$ U.S. Forest Service, Pacific Northwest Research Station, Corvallis Forestry Sciences Lab, Corvallis, Oregon; greeves@fs.fed.us, swondzell@fs.fed.us 


\section{Abstract}

Phenology can be linked to individual fitness, particularly in strongly seasonal environments where the timing of events have important consequences for growth, condition, and survival. We studied the phenology of Coho Salmon hatching and emergence in streams with contrasting thermal variability, but in close geographic proximity. Following emergence, we tracked body sizes of cohorts of young-of-year fish until the end of the growing season. Hatch and emergence timing occurred at the same time among streams with marked variability in thermal regimes. We demonstrate that this can be explained in part by the thermal units accumulated during embryo development. At the end of the first growing season there were some differences in body size,

52 however overall fish size among streams were similar despite strong differences in thermal regimes. Collectively these results provide novel insights into the interactions between environmental variability and the early life-history stages of Coho Salmon furthering our understanding of the consequences of phenology on growth and survival for individuals within the critical first summer of life. 


\section{Introduction}

The phenology of transitions in an individual's life cycle can have important

83

consequences for growth and survival, particularly in strongly seasonal environments (Einum and Fleming 2000; Love et al. 2010; Johansson et al. 2015). Strongly seasonal environmental conditions impose varying constraints on different life stages and a species' hatching or emergence phenology can evolve through natural selection to correspond with a suite of environmental conditions that maximize individual fitness (Stenseth and Mysterud 2002; Visser and Both 2005). Furthermore, because favorable environmental conditions for one life stage are not necessarily favorable for another (Schluter et al. 1991), it is important to evaluate connections between multiple stages in the life cycle for a comprehensive understanding of phenology.

Species such as salmon and trout are good subjects for the study of linked phenologies as their life cycles include multiple stages. The life cycle can involve both freshwater and marine environments with multiple transitions that must be timed to ensure growth opportunities for current and future life stages (Quinn 2005). Growth is important for the early life history of these species as prior work indicates that larger-bodied individuals are more likely to survive through the winter in freshwaters (Quinn and Peterson 1996; Berg et al. 2009) and within the marine environment (Moss et al. 2005; Wainwright and Weitkamp 2013). In this study, we focused on the phenology of freshwater life stages of Coho Salmon (Oncorhynchus kisutch), from hatching through the first summer of life. Within this timeframe we empirically examined multiple, linked phenologies, including hatch and emergence timings as well as the consequences of these phenologies on size near the end of the first growing season. 
104 (Elliott 1994; Quinn 2005). We focused our study on a high-latitude $\left(60^{\circ} \mathrm{N}\right)$ system

characterized by strongly defined spatial and seasonal patterns in stream thermal regimes. In this

106 system, Coho Salmon hatch and emerge in nearly adjacent streams that can have radically

107 different thermal regimes. Adjacent streams with contrasting thermal regimes range from

108 surface-water dominated streams that have high seasonal thermal variability to groundwater-

109 dominated streams that exhibit much lower thermal variability. In the streams we studied adults

110 return from the sea to spawn from early fall through early winter, with incubation occurring over

111 winter, hatching in the late-spring, and emergence occurring in the summer. We hypothesized

112 that hatching and emergence of salmon fry would be influenced by prior thermal regimes, which

113 have been demonstrated to influence embryo development and hatch timing in other settings

114 (Fuhrman et al. 2017). Further we predicted that fish would attain larger sizes at the end of the

115 growing season in the surface-water streams, as only these streams have temperatures favorable

116 for growth (Brett 1971; Stewart and Ibarra 1991; Armstrong et al. 2013). We addressed the

117 phenologies of the early stages in the salmon life cycle (hatching and emergence) and their

118 consequences for individuals within the critical first summer of life (Elliott 1994; Fuiman and

119 Werner 2002; Armstrong and Nislow 2006). Collectively, results of this work provide a unique

120 evaluation of linkages between phenologies of successive life stages in a species with a complex

121 life cycle that plays out in a highly variable environment.

122

123 Materials and Methods

Our study streams were located on the west Copper River Delta, south-central Alaska,

125 USA, these are: 18 Mile Creek (N60.45882 $\left.{ }^{\circ} \mathrm{W} 145.29285^{\circ}\right)$, Blackhole Creek 
126

127

128

129

130

$\left(\mathrm{N} 60.44695^{\circ} \mathrm{W} 145.23999^{\circ}\right)$, Hatchery Creek $\left(\mathrm{N} 60.59112^{\circ} \mathrm{W} 145.63542^{\circ}\right)$, Salmon Creek $\left(\mathrm{N} 60.45485^{\circ} \mathrm{W} 145.17139^{\circ}\right)$, and 25 Mile Creek $\left(\mathrm{N} 60.44176^{\circ} \mathrm{W} 145.11794^{\circ}\right)$. Within each stream, a 200m study reach was selected based on the presence of young-of-year Coho Salmon, accessibility to the site; and general similarities between sites including riparian vegetation, stream size, slope, and discharge. We assessed differences in thermal variability among streams with continuous year-round monitoring using water temperature data loggers (HOBO Pro, U-22 model, Onset Corp., Pocasset, Massachusetts, USA). All loggers were encased in a galvanized pipe $(6.3 \mathrm{~cm} \times 15.2 \mathrm{~cm})$ for protection and attached by steel cables to anchors that were driven into the stream bed to withstand frequent storms and high-flows. Four data loggers were deployed within the main-channel spawning habitat of each stream and recorded water temperature at hourly intervals from September 1, 2012 to December 31, 2013 in 18 Mile, Hatchery, Salmon, and 25 Mile Creeks; and from April 1, 2013 to December 31, 2013 in Blackhole Creek. Due to hazardous weather conditions and presence of brown bears (Ursus arctos horribilis) during the spawning season, it was impossible to conduct comprehensive spawning surveys.

Once emerged, Coho salmon were collected twice each month from April to October in 2013 using baited minnow traps and dip nets. Fish were measured (fork-length, mm) and released, except for a random sub-set of 10 fish per stream during each month. These 10 fish were euthanized with tricaine methanesulfonate (MS-222) and kept frozen for analysis of hatch and emergence dates using otoliths (Fuiman and Werner 2002). We analyzed a total of 122 otoliths to determine hatch and emergence dates among the study streams. Sagittal otoliths were mounted on a frosted glass slide with Crystal Bond@ heated thermoplastic cement (SPI Supplies, West Chester, Pennsylvania, USA) and wet-polished with $0.3 \mu \mathrm{m}$ grit paper and buffed with 
149 aluminum oxide micro-polish until daily ring increments were discernible. Otoliths were 150 analyzed under a compound microscope (Leica DMLS, Buffalo Grove, Illinois, USA) using

151 image analysis software (Image-Pro version 7.0, Media Cybernetics, Rockville, Maryland, 152 USA). Ages were estimated by counting each complete daily increment starting outside the 153 primordia and counting outward in a straight trajectory to the last visible ring. Counts were 154 conducted by two independent readers to clarify the count estimate. We used the daily increment 155 technique, which is a well-recognized and widely used tool for fish age estimates (Panella 1971; 156 Jones 1992; Fuiman and Werner 2002). Age validation (Beamish and McFarlane 1983; Campana 157 2001) was not possible due to logistical difficulty and the inability to obtain permits to 158 chemically tag wild fish or mark and recapture known age fish. Once the ages were estimated, 159 we subtracted the estimated age from the date of capture to determine hatch and emergence 160 timing (Fuiman and Werner 2002). In a separate analysis of emergence timing, we calculated a cumulative frequency distribution (CDF) of emergence timing for each stream, based on measurements of body lengths 163 (fork length, $\mathrm{mm}$ ) pooled across samples collected at regular intervals every two weeks 164 throughout the spring, summer, and fall. For each stream, the estimated CDF reflected the cohort 165 emergence dates or the proportion of fish having body lengths $<35 \mathrm{~mm}$, assessed during sampling 166 events over the study period. We chose $35 \mathrm{~mm}$ to represent when fish had emerged based on the 167 size of fish whose yolk sacs were fully absorbed during our field observations. One-way analysis 168 of variance (ANOVA) based on ranks and Dunn's pair-wise comparisons were used to assess the 169 significance of differences in dates of hatching, emergence, and fish size among streams.

170 Differences in body size of juvenile salmon were determined by comparing mean lengths of all 171 juvenile salmon measured in each stream in late October. 
172

173

174

175

176

177

178

179

180

181

\section{Results}

There were clear seasonal differences in thermal regimes among the five study streams (Figures $1 \& 2$ ). 18 Mile and Blackhole Creeks were dominated by surface-water and showed higher annual thermal variation relative to the stable, groundwater-dominated thermal regimes of Hatchery, Salmon, and 25 Mile Creeks. The thermal incubation environment was similar in 18 Mile and Blackhole Creeks and showed relatively high thermal variation during embryo incubation. Hatchery Creek was different from all other creeks and showed an intermediate level of thermal variability. The thermal incubation environment was statistically similar in Salmon and 25 Mile Creeks and showed the lowest thermal variation during embryo incubation.

Neither hatch dates ( $p=0.79$; Figure 3$)$, nor the fry emergence dates ( $p=0.998$; Figure 4$)$ differed significantly among streams. The cumulative frequency distribution of cohort emergence dates (Figure 5) largely corroborated the otolith-determined emergence timing; in all but one stream, the cohort emergence dates fit within the $95 \%$ CI of the otolith-determined emergence dates (Figure 4). The exception was Hatchery Creek in which size-determined (cohort) emergence dates occurred later than all other streams. There were differences in the mean juvenile body lengths among streams whereby juveniles in 25 Mile and Salmon Creeks were significantly larger than fish in Hatchery Creek $(p<0.001$; Figure 6).

\section{Discussion}

We sought to understand linkages between thermal heterogeneity of surface-water and groundwater streams on the Copper River Delta, AK and the phenology of Coho Salmon. There were important differences in the thermal incubation environment for embryos among the 
195 196

surface-water and groundwater streams. The thermal incubation environment was similar in 18 Mile and Blackhole Creeks where both creeks showed relatively high thermal variation; in contrast Salmon and 25 Mile Creeks exhibited low thermal variation during winter incubation and throughout the rest of the year. We predicted that phenologies may vary among streams as species inhabiting a wide range of winter thermal conditions may adopt variable tactics based in part on variable phenologies (Shuter et al. 2012). However, despite the observed thermal differences we found a relatively synchronized spring hatch timing and summer emergence timing among streams. Across all streams, the timing of egg hatching ranged from mid-April to June, and fry emergence occurred from June to August.

Synchronous hatch and emergence phenology among streams may be driven by the timing of peak availability of food resources to young-of-year Coho Salmon (Einum and Fleming 2000; Letcher et al. 2004; Wipfli and Baxter 2010) as well as the need to attain sufficient size (Quinn and Peterson 1996) and condition (Berg et al. 2009) to survive the winter (Campbell 2017). Although we observed the same hatch and emergence timing among streams with a peak emergence time in the summer (July), the distribution of emergence timing was wide and the full range of emergence timing in all streams spanned from late spring to late fall, which may be due to genetic or environmental differences among individuals within and among redds in each stream (Steel et al. 2012; Sear et al. 2014; Fuhrman et al. 2017).

In our system, earlier emergence of juveniles could give them more time to attain size and condition. In high-latitude environments, time may be considered as the product of photoperiod and number of days in the growing season, during which conditions are conducive to growth (e.g., food availability, physiologically favorable temperatures; Armstrong et al. 2016). Surprisingly, we found that many fish emerged well past the summer solstice, thus missing the 
218 longest days of the year and substantially shortening the length of time available to forage in the 219 stream during the summer growing season (Villarreal et al. 1988; Veras et al. 2013; Kitagawa et 220 al. 2015). This suggests other potential constraints on earlier emergence in this system, which 221 could include lack of habitat available to earlier emerging individuals due to persistence of ice in 222 main-channel and off-channel habitats (Brown et al. 2011) or low food availability in early 223 spring (Wipfli 1997; Rine et al. 2016; Campbell 2017).

225 pattern that has been more widely reported in other organisms (Liebhold et al. 2004). Synchrony 226 of phenologies has also been shown to occur in parallel with the timing of food supplies, for 227 example as in insect-host plant interactions (Dewar and Watt 1991; VanAsch and Visser 2006; 228 Elzinga et al. 2007), or fledging of birds in concert with high densities of insect prey (Williams et al. 2015). The window for growth of emerging Coho Salmon is relatively short in Alaska, and 230 it is reasonable to assume the capacity of individuals to grow within this brief window is at a 231 premium (Armstrong et al. 2016).

We considered previous observations of spawn timing in conjunction with Accumulated 233 Thermal Unit (ATU) models (Murray and McPhail 1987) and found that previously reported 234 ATUs required for hatching, or assumed spawn timings, do not fully describe the variability that 235 we observed in hatch and emergence phenology. The ATU models of Murray and McPhail 236 (1987) were based on laboratory studies whereas embryo incubation conditions in the field may 237 be much more variable. Accordingly, it seems reasonable to hypothesize that variability in 238 incubation timing cannot be explained by ATU requirements alone. Further, past work reveals 239 plasticity in temperature (ATU) requirements for embryo incubation both among locations and 
240 among individuals (Alderdice and Velsen 1978; Farrell et al. 2008; Eliason et al. 2011; Steel et 241 al. 2012).

Studies have found a link between temperature and spawning (Crozier et al. 2008;

243 Eliason et al 2011). Thus, variation in spawn timing can be of adaptive significance and may 244 relate to optimal timing of fry emergence or improve fitness during other portions of the life 245 cycle (Heggberget 1988; Jensen et al. 1991; Web et al. 1996; Rodgers and Schindler 2008).

246 There is some un-published evidence of earlier spawning runs in the surface-water streams and 247 later spawning runs in the groundwater streams of the Copper River Delta, AK (K. Hodges U.S. 248 Forest Service, Chugach National Forest, personal communication). A difference in spawn 249 timing such as this would allow for a synchronized hatch timing due to differences in incubation 250 time and the rate of thermal unit accumulation. In an environment as heterogeneous and complex 251 as the Copper River Delta it is likely there are several interacting factors that determine salmon 252 phenology. More detailed information on spawn timing and incubation (e.g., capping redds to 253 track emergence) is needed to understand the full effects of temperature on that portion of the life 254 cycle (Braun et al. 2013) in our study system.

255 At the end of the first summer growing season, we observed significant differences in the 256 sizes of young-of-year fish among streams. The smallest fish were in Hatchery Creek, and the 257 largest fish were in Salmon and 25 Mile Creeks. Hatchery Creek is further away from the other 258 streams and may have smaller fish at the end of the growing season due to differences in 259 geography, hydrology, trophic influences, or other unknown factors. In contrast juveniles were 260 largest at the end of the summer in the groundwater dominated Salmon and 25 Mile Creeks. Our 261 results contradict our prediction that fish would attain larger sizes at the end of the growing 262 season in the surface-water streams, as only these streams have temperatures favorable for 
263 growth (Brett 1971; Stewart and Ibarra 1991; Armstrong et al. 2013). Perhaps these groundwater

264 sites provide an ideal thermal environment for growth, or have more abundant prey for juveniles

265 to feed on. Further investigation of these factors would be needed to more clearly elaborate how

266 conditions in summer interact with the timing of emergence to drive size and condition of fish

267 entering into winter (Campbell 2017). It is important to note that the absolute size difference at

268 the end of the first growing season was relatively small (1-3mm) among streams and perhaps

269 these statistical differences are of little biological significance. Variation in body size is known

270 to be attributed to a host of factors, including size-biased survival or movement, variability in

271 food availability, bioenergetics, habitat quality, water temperature, and other potential biotic or

272 abiotic factors in play during the summer growth season (Björnsson et al. 1989; Jensen et

273 al.1991; Sandercock 1991; Rosenfeld et al. 2005; Quinn 2005).

274

As the focus on climate vulnerability of salmon grows in the region (e.g., Leppi et al.

275 2014; Shanley et al. 2014; Wobus et al. 2016; Sloat et al. 2017) there is a need to continue

276 expanding our knowledge of this complex issue. Our results allowed us to evaluate linkages

277 between multiple stages in the salmon life cycle and understand the consequences of phenology

278 for individuals during the first summer of life. Climate change will continue to alter

279 environmental conditions in streams within the region (Beamer et al. 2017), likely shifting the

280 seasonal activities of organisms with potential consequences to their fitness and life history

281 trajectories (Kovach et al. 2015; Power 2002; Visser and Both 2005). For species such as Coho

282 Salmon, which use multiple habitats for multiple life stages, the effects of climate-related

283 variability may be particularly challenging to fully describe (Wainwright and Weitkamp 2013).

284 Furthermore, the effects of climate-related changes are unlikely to be consistent across life stages

285 and conflicting selection pressures are a distinct possibility (Schluter et al. 1991). Results of this 
286 research provide novel insights into the linkages between thermal variability and Coho Salmon

287 phenology in a heterogeneous landscape. We hope this work inspires further studies which are 288 needed to fully describe the complexities embedded within the salmon life cycle.

289

290

291

292

293

294

295

296

297

298

299

300

301

302

303

304

305

306

307

308 


\section{Acknowledgements:}

We thank C. Salazar, K. Kirkby, A. Morin, L. Adelfio, L. Hotca, C. Malstrom, K.

311 Hodges, D. Kuntzsch, S. Meade, M. Sloat, C. Zimmerman, M. Heck, S. Johnson, C. Marshall,

312 the Fisheries and Wildlife Department at Oregon State University, and the entire Cordova

313 Ranger District of the Chugach National Forest. Thanks to K. Christiansen for providing the

314 study map. This research was permitted by Oregon State University ACUP \#4364. We are

315 grateful to our funding sources: The National Fish and Wildlife Foundation, the U.S. Department

316 of Agriculture Forest Service PNW Research Station, and the Environmental Protection Agency

317 Science to Achieve Results (STAR) Fellowship. Use of trade or firm names is for descriptive

318 purposes only and does not constitute endorsement of any product or service by the U.S.

319 Government.

320

321

322

323

324

325

326

327

328

329

330

331

332

333 


\section{References:}

Alderdice, D.F. and Velsen, F.P.J. 1978. Relation between temperature and incubation time for eggs of Chinook Salmon (Oncorhynchus tshawytscha) J. Fish. Res. Board Can. 35: 69-75.

Arismendi, I., Johnson, S.L., Dunham, J.B., Haggerty, R., and Hockman-Wert, D. 2012. The paradox of cooling streams in a warming world: Regional climate trends do not parallel variable local trends in stream temperature in the Pacific Continental United States. Geophys. Res. Letters. 39 DOI: L10401 10.1029/2012g1051448

Armstrong, J.D. and Nislow, K.H. 2006. Critical habitat during the transition from maternal provisioning in freshwater fish, with emphasis on Atlantic salmon (Salmo salar) and brown trout (Salmo trutta). J. Zool. 269(4): 403-413. doi: 10.1111/j.1469-7998.2006.00157x.

Armstrong, J.B. and Schindler, D.E. 2013. Going with the flow: Spatial distributions of juvenile Coho Salmon track an annually shifting mosaic of water temperature. Ecosystems. doi:10.1007/s10021-013-9693-9.

Armstrong, J.B., Takimoto, G., Schindler, D.E., Hayes, M.M., and Kauffman, M.J. 2016. Resource waves: phenological diversity enhances foraging opportunities for mobile consumers. Ecology. 97(5): 1099-1112.

Beamer, J.P., Hill, D.F., McGrath, D., Arendt, A. and Kienholz, C., 2017. Hydrologic Impacts of changes in climate and glacier extent in the Gulf of Alaska watershed. Water Resources Research.

Beamish, R.J. and McFarlane, G.A. 1983. The forgotten requirement for age validation in fisheries biology. Trans. Am. Fish. Soc. 112(6): 735-743.

Berg, O.K., Finstad, A.G., Solem, Ø., Ugedal, O., Forseth, T., Niemelä, E., Arnekleiv, J.V., Lohymann, A., and Næsje, T.F. 2009. Pre-winter lipid stores in young-of-year Atlantic salmon along a north-south gradient. J. Fish Bio. 74(7): 1383-1393.

Björnsson, B.T., Thorarensen, H., Hirano, T., Ogasawara, T., and Kristinsson, J.B. 1989. Photoperiod and temperature affect plasma growth hormone levels, growth, condition factor and hypoosmoregulatory ability of juvenile Atlantic Salmon (Salmo salar) during parr-smolt transformation. Aquaculture. 82: 77-91.

Braun, D.C., Patterson, D.A., and Reynolds, J.D. 2013. Maternal and environmental influences on egg size and juvenile life-history traits in Pacific salmon. Ecol. and Evol. 3(6): 1727-1740.

Brett, J.R. 1971. Energetic responses of salmon to temperature. A study of some thermal relations in physiology and freshwater ecology of sockeye salmon (Oncorhynchus nerka). Amer. Zoo. 11: 99-113. 
Brown, R.S., Hubert, W.A., and Daly, S.F. 2011. A primer on winter, ice, and fish: what fisheries biologists should know about winter ice processes and stream-dwelling fish. Fisheries. 36(1), pp.8-26.

Campana, S.E. 2001. Accuracy, precision and quality control in age determination, including a review of the use and abuse of age validation methods. J. Fish Bio. 59: 197-242. doi:10.1006/jfbi.2001.1668.

Campbell, E.Y. 2017. Influences of Thermal and Trophic Heterogeneity on Phenology, Growth and Resource Use by Juvenile Coho Salmon, Ph.D. Dissertation, Oregon State University, Corvallis, OR, USA.

Crozier, L.G., Hendry, A.P., Lawson, P.W., Quinn, T.P., Mantua, N.J., Battin, J., Shaw, R.G., and Huey, R.B. 2008. Potential responses to climate change in organisms with complex life histories: evolution and plasticity in Pacific salmon. Evol. Appl. 1(2): 252-270.

Dewar, R.C. and Watt, A.D. 1991. Predicted changes in the synchrony of larval emergence and budburst under climatic warming. Oecologia. 89(4): 557-559.

Einum, S. and Fleming, I.A. 2000. Selection against late emergence and small offspring in Atlantic salmon (Salmo salar). Evolution, 54(2): 628-639.

Eliason, E.J., Clarck, T.D., Hague, M.J., Hanson, L.M., Gallagher, Z.S., Jeffries, K.M., Gale, M.K., Patterson, D.A., Hinch, S.G., and Farrell, A.P. 2011. Differences in thermal tolerance among sockeye salmon populations. Science. 332: 109-112.

Elliott, J.M. 1994. Quantitative ecology and the brown trout. Oxford University Press, Oxford.

Elzinga, J.A., Atlan, A., Biere, A., Gigord, L., Weis, A.E., and Bernasconi, G. 2007. Time after time: flowering phenology and biotic interactions. Trends in Ecol. and Evol. 22(8): 432-439.

Farrell, A.P., Hinch, S.G., Cooke, S.J., Patterson, D.A., Crossin, G.T., Lapointe, M., and Mathes, M.T. 2008. Pacific salmon in hot water: applying aerobic scope models and biotelemetry to predict the success of spawning migrations. Physiol. Biochem. Zool. 81(6): 697-708.

Flitcroft, R.L., Lewis, S.L., Arismendi, I., LovellFord, R., Santelmann, M.V., Safeeq, M., and Grant, G. 2016. Linking hydroclimate to fish phenology and habitat use with ichthyographs. PLoS ONE. 11(12): e0168831. Doi:10.1371/journal.pone.0168831.

Fuiman, L.A. and Werner, R.G. 2002. Fishery Science: The Unique Contributions of Early Life Stages. Blackwell Publishing, Oxford.

Fuhrman, A.E., Larsen, D.A., Steel, E.A., Young, G. and Beckman, B.R. 2017. Chinook salmon emergence phenotypes: Describing the relationships between temperature, emergence timing and condition factor in a reaction norm framework. Ecol. Freshwater Fish DOI: 10.111/eff.12351. 
Giannico, G.R. 2000. Habitat selection by juvenile coho salmon in response to food and woody debris manipulations in suburban and rural stream section. Can. J. Fish. Aquat. Sci. 57: 18041813.

Gienapp, P., Reed, T.E., and Visser, M.E. 2014. Why climate change will invariably alter selection pressures on phenology. Proc. Royal Soc. B. 281:20141611. http://dx.doi.org/10.1098/rspb.2014.1611

Godin, J.G. 1982. Migrations of salmonid fishes during early life history phases: daily and annual timing. In: Proceedings of the Salmon and Trout Migratory Behavior Symposium 1981. University of Washington. Eds. E.L. Brannon and E.O. Salo. School of Fisheries, University of Washington, Seattle, Washington.

Heggberget, T.G. 1988. Timing of spawning in Norwegian Atlantic salmon (Salmo salar). Can. J. Fish. Aquat. Sci. 45: 845-849.

Hertel, S. 2016. Aquatic insect community structure and secondary production in southcentral Alaska streams with contrasting thermal and hydrological regimes, Master's Thesis, Loyola University Chicago, Chicago, Illinois, USA.

Hodge, B.W., Wilzbach, M.A., Duffy, W.G., Quiñones, R.M., and Hobbs, J.A. 2016. Life history diversity in Klamath River steelhead. Trans. Am. Fish. Soc. 145(2): 227-238. doi:10.1080/00028487.2015.1111257.

Isaak, D.J., Wollrab, S., Horan, D., and Chandler, G. 2011. Climate change effects on stream and river temperatures across the northwest U.S. from 1980-2009 and implications for salmonid fishes. Climatic Change. doi: 10.1007/s10584-011-0326-z

Jensen, A.J., Johnsen, B.O., and Heggberget, T.G. 1991. Initial feeding time of Atlantic salmon, Salmo salar, alevins compared to river flow and water temperature in Norwegian streams. Environ. Biol. Fishes. 30: 379-385.

Johansson, J., Nilsson, J., and Jonzen, N. 2015. Phenological change and ecological interactions: an introduction. Oikos. 124: 1-3.

Jones, C.M. 1992. Development and application of the otolith increment technique, pp. 1-11. In Otolith microstructure examination and analysis (Stevenson, D.K. and Campana, S.E., eds.). Can. Spec. Publ. Fish. Aquat. Sci. 117.

Kitagawa, A.T., Costa, L.S., Paulino, R.R., Luz, R.K., Rosa, P.V., Guerra-Santos, B., FortesSilva, R. 2015. Feeding behavior and the effect of photoperiod on the performance and hematological parameters of the pacamã catfish (Lophiosilurus alexandri). Appl. Anim. Behav. Sci. 171: 211-218. 
Kovach, R.P., Ellison, S.C., Pyare, S. and Tallmon, D.A., 2015. Temporal patterns in adult salmon migration timing across southeast Alaska. Global change biology, 21(5), pp.1821-1833.

Leppi, J.C., Rinella, D.J., Wilson, R.R. and Loya, W.M., 2014. Linking climate change projections for an Alaskan watershed to future coho salmon production. Global change biology, 20(6), pp.1808-1820.

Letcher, B.H., Dubreuil, T., O’Donnell, M.J., Obedzinski, M., Griswold, K., and Nislow, K.H. 2004. Long-term consequences of variation in timing and manner of fry introduction on juvenile Atlantic salmon (Salmo salar) growth, survival, and life-history expression. Can. J. Fish. Aquat. Sci. 61: 2288-2301.

Liebhold, A., Koenig, W.D., and Bjørnstad, O.N. 2004. Spatial synchrony in population dynamics. Ann. Rev. Ecol., Evol., and Syst. 35: 467-490.

Dio:10.1146/annurev.ecolsys.34.011802.132516.

Love, O.P., Gilchrist, H.G., Descamps, S., Semeniuk, C.A.D., and Bêty, J. 2010. Pre-laying climatic cues can time reproduction to favorablely match offspring hatching and ice conditions in an Arctic marine bird. Oecologia. 164: 277-286. doi:10.1007/s00442-010-1678-1

Moss, J.H., Beauchamp, D.A., Cross, A.D., Myers, K.W., Farley, E.V., Murphy, J.M., and Helle, J.H. 2005. Evidence for size-selective mortality after the first summer of ocean growth by pink salmon. Trans. Am. Fish. Soc. 134: 1313-1322. doi: 10.1577/T05-054.1

Murray, C.B. and McPhail, J.D. 1987. Effect of incubation temperature on the development of five species of Pacific salmon (Oncorhynchus) embryos and alevins. Can. J. Zoo., 66: 266-273.

Panella, G. 1971. Fish otoliths: daily growth layers and periodical patterns. Science. 173(4002): 1124-1127.

Penaluna, B.E., Dunham, J.B., Railsback, S.F., Arismendi, I., Johnson, S.L., Bilby, R.E., Safeeq, M., and Skaugset, A.E. 2015. Local Variability Mediates Vulnerability of Trout Populations to Land Use and Climate Change. PLoS ONE 10(8): e0135334.

https://doi.org/10.1371/journal.pone.0135334

Pörtner, H.O. and Farrell, A.P. 2008. Physiology and Climate Change. Ecology. 322: 690-692.

Power, G. 2002. Charrs, glaciations and seasonal ice. Environ. Biol. Fishes. 64: 17-35. doi: 10.1023/A:1016066519418

Quinn, T.P. and Peterson, N.P. 1996. The influence of habitat complexity and fish size on overwinter survival and growth of individually marked juvenile Coho Salmon (Oncorhynchus kisutch) in Big Beef Creek, Washington. Can. J. Fish. Aquat. Sci. 53: 1555-1564. 
Quinn, T.P. 2005. The behavior and ecology of Pacific salmon and trout. University of Washington Press, Seattle, Washington.

Rine, K.M., Wipfli, M.S., Schoen, E.R., Nightengale, T.L., and Stricker, C.A. 2016. Trophic pathways supporting juvenile Chinook and Coho salmon in the glacial Susitna River, Alaska: patterns of freshwater, marine, and terrestrial food resource use across a seasonally dynamic habitat mosaic. Can. J. Fish. Aquat. Sci. 73: 1626-1641. dx.doi.org/10.1139/cjfas-2015-0555.

Rodgers, L.A. and Schindler, D.E. 2008. Asynchrony in population dynamics of sockeye salmon in southwest Alaska. Oikos. 117: 1578-1586

Rosenfeld, J.S., Leiter, T., Lindner, G., and Rothman, L. 2005. Food abundance and fish density alters habitat selection, growth, and habitat suitability curves for juvenile coho salmon (Oncorhynchus kisutch). Can. J. Fish. Aquat. Sci. 62: 1691-1701. doi:10.1139/F05-072.

Sandercock, D. 1991. Coho Salmon Life History in Pacific Salmon Life Histories. Eds: Groot, C. and L. Margolis. UBC Press, British Columbia.

Schluter, D., Price, T.D., and Rowe, L. 1991. Conflicting selection pressures and life history trade-offs. Proc. Royal Soc. B. 246: 11-17.

Sear, D.A., Pattison, I., Collins, A.L., Newson, M.D., Jones, J.I., Naden, P.S., and Carling, P.A. 2014. Factors controlling the temporal variability in dissolved oxygen regime of salmon spawning gravels. Hydrol. Process. 28(1). Pp. 86-103.

Shanley, C.S. and Albert, D.M., 2014. Climate change sensitivity index for Pacific salmon habitat in southeast Alaska. PLoS One, 9(8), p.e104799.

Shuter, B.J., Finstad, A.G., Helland, I.P., Zweimüller, I., and Hölker, F. 2012. The role of winter phenology in shaping the ecology of freshwater fish and their sensitivities to climate change. Aquat. Sci. doi:10.1007/s00027-012-0247-3.

Sloat, M.R., Reeves, G.H. and Christiansen, K.R., 2017. Stream network geomorphology mediates predicted vulnerability of anadromous fish habitat to hydrologic change in southeast Alaska. Global change biology, 23(2), pp.604-620.

Stanford, J.A., Anderson, M.L., Reid, B.L., Chilcote, S.D., and Bansak, T.S. 2016. Thermal diversity and the phenology of floodplain aquatic biota. River Science: Research and Management for the $21^{\text {st }}$ Century. doi: 10.1002/9781118643525.ch13.

Steel, E.A., Tillotson, A., Larsen, D.A., Fullerton, A.H., Denton, K.P., and Beckman, B.R. 2012. Beyond the mean: The role of variability in predicting ecological effects of stream temperature on salmon. Ecosphere 3(11): 1-11. 
Stenseth, N.C. and Mysterud, A. 2002. Climate, changing phenology, and other life history traits: nonlinearity and match-mismatch to the environment. Proc. Nat. Acad. Sci. of N. Amer. 99: 13379-13381.

Stewart, D.J. and Ibarra, M. 1991. Predation and production by salmonine fishes in Lake Michigan, 1978-88. Can. J. Fish. Aquat. Sci. 48: 909-922.

VanAsch, M. and Visser, M.E. 2006. Phenology of forest caterpillars and their host trees: the importance of synchrony. Ann. Rev. Entomol. 52: 37-55.

Veras, G.C., Murgas, L.D.S., Rosa, P.V., Zangeronimo, M.G., Ferreira, M.S.S., Leon, J.A.S. 2013. Effect of photoperiod on locomotor activity, growth, feed efficiency and gonadal development of Nile tilapia. R. Bras. Zootec. 42(12): 844-849.

Villarreal, C.A., Thorp, J.E., Miles, M.S. 1988. Influence of photoperiod on growth changes in juvenile Atlantic salmon, Salmo salar L. J. Fish Bio. 33(1): 15-30.

Visser, M.E. and Both, C. 2005. Review. Shifts in phenology due to global climate change: the need for a yardstick. Proc. Royal Soc. of London B- Biol. Sci. 272: 2561-2569.

Wainwright, T.C. and Weitkamp, L.A. 2013. Effects of climate change on Oregon coast Coho Salmon: Habitat and life-cycle interactions. Northwest Sci. 87(3): 219-242. doi:10.3955/046.087.0305

Web, J.H. and McLay, H.A. 1996. Variation in the time of spawning of Atlantic salmon (Salmo salar) and its relationship to temperature in the Aberdeenshire Dee, Scotland. Can. J. Fish. Aquat. Sci. 53: 2739-2744.

Williams, T.D., Bourgeon, S., Cornell, A., Ferguson, L., Fowler, M., Fronstin, R.B., and Love, O.P. 2015. Mid-winter temperatures, not spring temperatures, predict breeding phenology in the European starling Sturnus vulgaris. Royal Soc. Open Sci. 2:140301.

Wipfli, M.S. 1997. Terrestrial invertebrates as salmonid prey and nitrogen sources in streams: contrasting old-growth and young-growth riparian forests in southeastern Alaska, USA. Can. J. Fish. Aquat. Sci. 54(6), pp.1259-1269.

Wipfli, M.S. and Baxter, C.V. 2010. Linking ecosystems, food webs, and fish production" subsides in salmonid watersheds. Fisheries. 35(8): 373-387. Doi.org/10.1577/1548-844635.8.373

Wobus, C., Prucha, R., Albert, D., Woll, C., Loinaz, M., et al. 2016. Correction: Hydrologic alterations from climate change inform assessment of ecological risk to pacific salmon in Bristol Bay, Alaska. PLoS One. 11(1): e0147242 
604

605

606

607

608

609

610

611

612

613

614

615

616

617

618

619

620

621

622

623

624

625

626

627

628

629

630

631

632

633

634

635

636

637

638

639

640

641

642

643

644

645
List of Figures:

Figure 1. Location of study streams on the Copper River Delta, Alaska. Surface-water streams: 18 Mile and Blackhole Creeks and Groundwater streams: Hatchery, Salmon, and 25 Mile Creeks. Map Credit: K. Christiansen.

Figure 2. Water temperatures $\left({ }^{\circ} \mathrm{C}\right)$ collected from the main-channel of the study streams on the Copper River Delta, Alaska from September 1, 2012 to December 31, 2013. Surface-water (SW) streams: 18 Mile and Blackhole Creeks and Groundwater (GW) streams: Hatchery, Salmon, and 25 Mile Creeks.

Figure 3. Estimated time of hatching of Coho Salmon in the study streams on the Copper River Delta, Alaska. Surface-water (SW) streams: 18 Mile and Blackhole Creeks and Groundwater (GW) streams: Hatchery, Salmon, and 25 Mile Creeks. Box and whisker plots show the median (middle line), first quartile (bottom of box), third quartile (top of box), and the minimum and maximum data points (whiskers).

Figure 4. Estimated time of emergence of Coho Salmon in the study streams on the Copper River Delta, Alaska. Surface-water (SW) streams: 18 Mile and Blackhole Creeks and Groundwater (GW) streams: Hatchery, Salmon, and 25 Mile Creeks. Box and whisker plots show the median (middle line), first quartile (bottom of box), third quartile (top of box), and the minimum and maximum data points (whiskers). " $X$ " is the median emergence time in each stream based on a size cut-off ( $35 \mathrm{~mm}$ and below).

Figure 5. Estimated time of emergence time of Coho Salmon in the study streams on the Copper River Delta, Alaska using a size cut-off of $<35 \mathrm{~mm}$ (cohort emergence dates) for emerging Coho Salmon. Surface-water (SW) streams: 18 Mile and Blackhole Creeks and Groundwater (GW) streams: Hatchery, Salmon, and 25 Mile Creeks.

Figure 6. Length (mm) (fork) of Coho Salmon fry at the end of the growing season (October) in the study streams on the Copper River Delta, Alaska. Surface-water (SW) streams: 18 Mile and Blackhole Creeks and Groundwater (GW) streams: Hatchery, Salmon, and 25 Mile Creeks. Box and whisker plots show the median (middle line), first quartile (bottom of box), third quartile (top of box), and the minimum and maximum data points (whiskers). 
Figure 1.

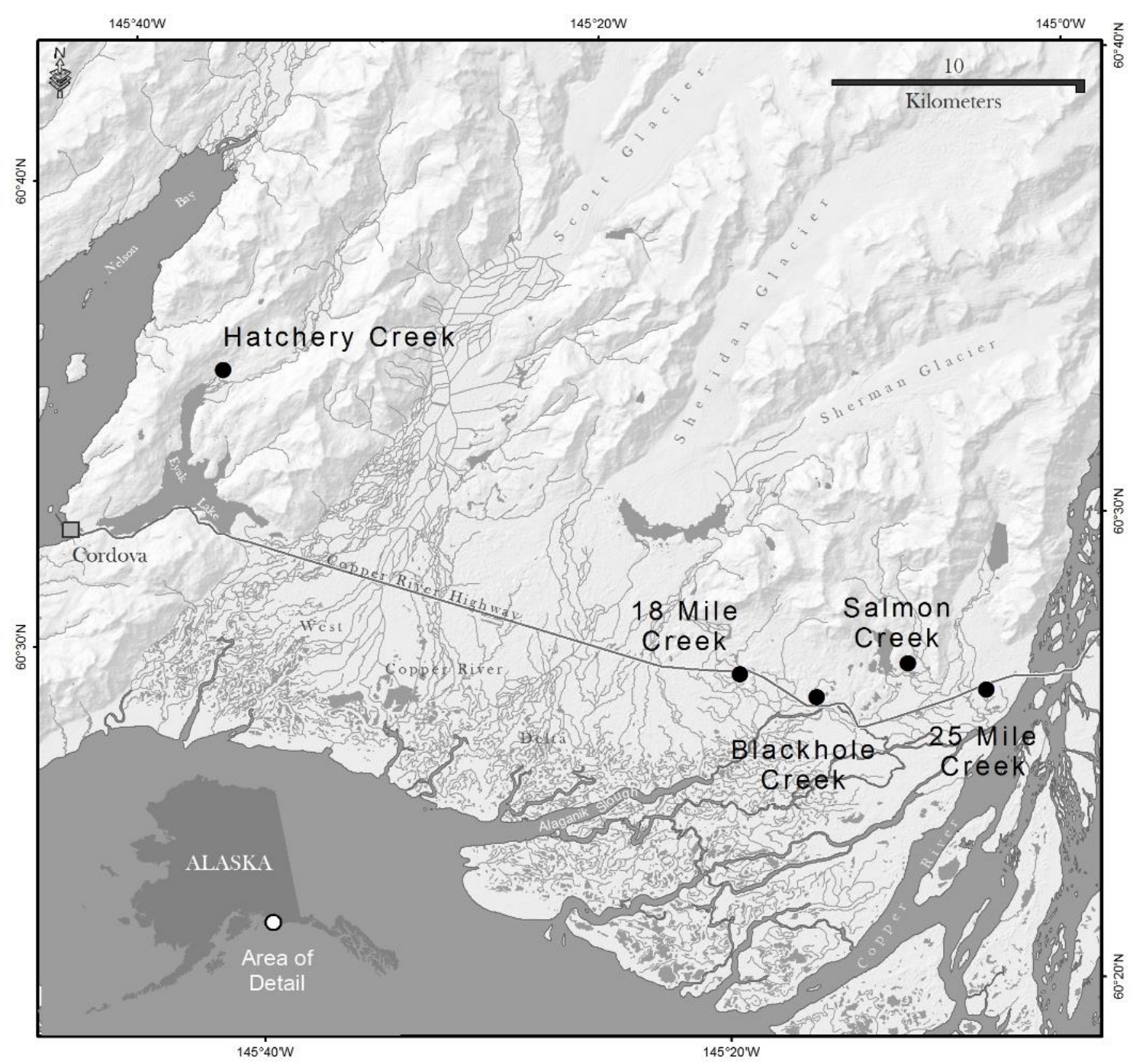


Figure 2.

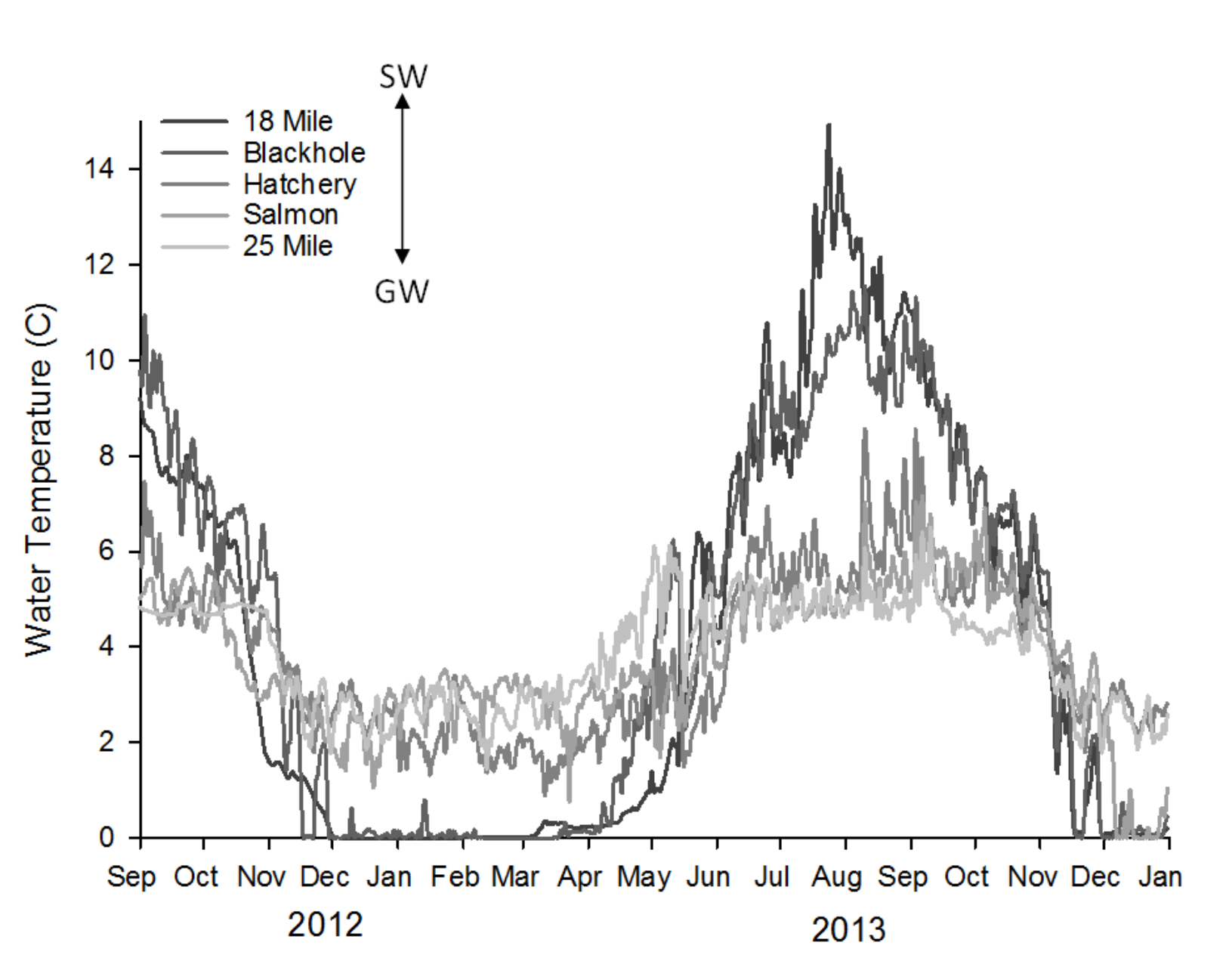

655

656

657

658

659

660

661

662

663

664 
Figure 3.

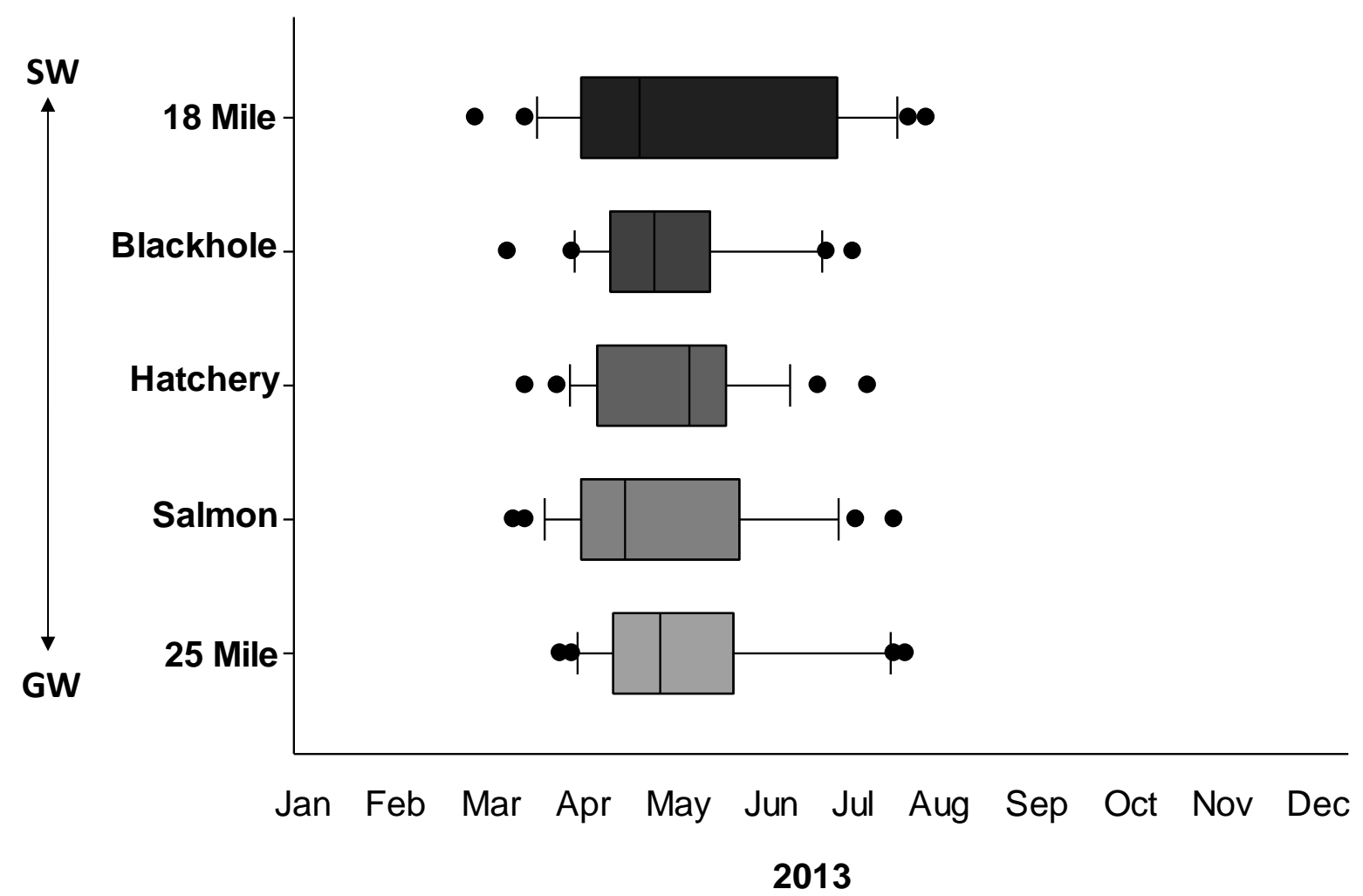

665

671

672

673

674

675

676 
Figure 4.

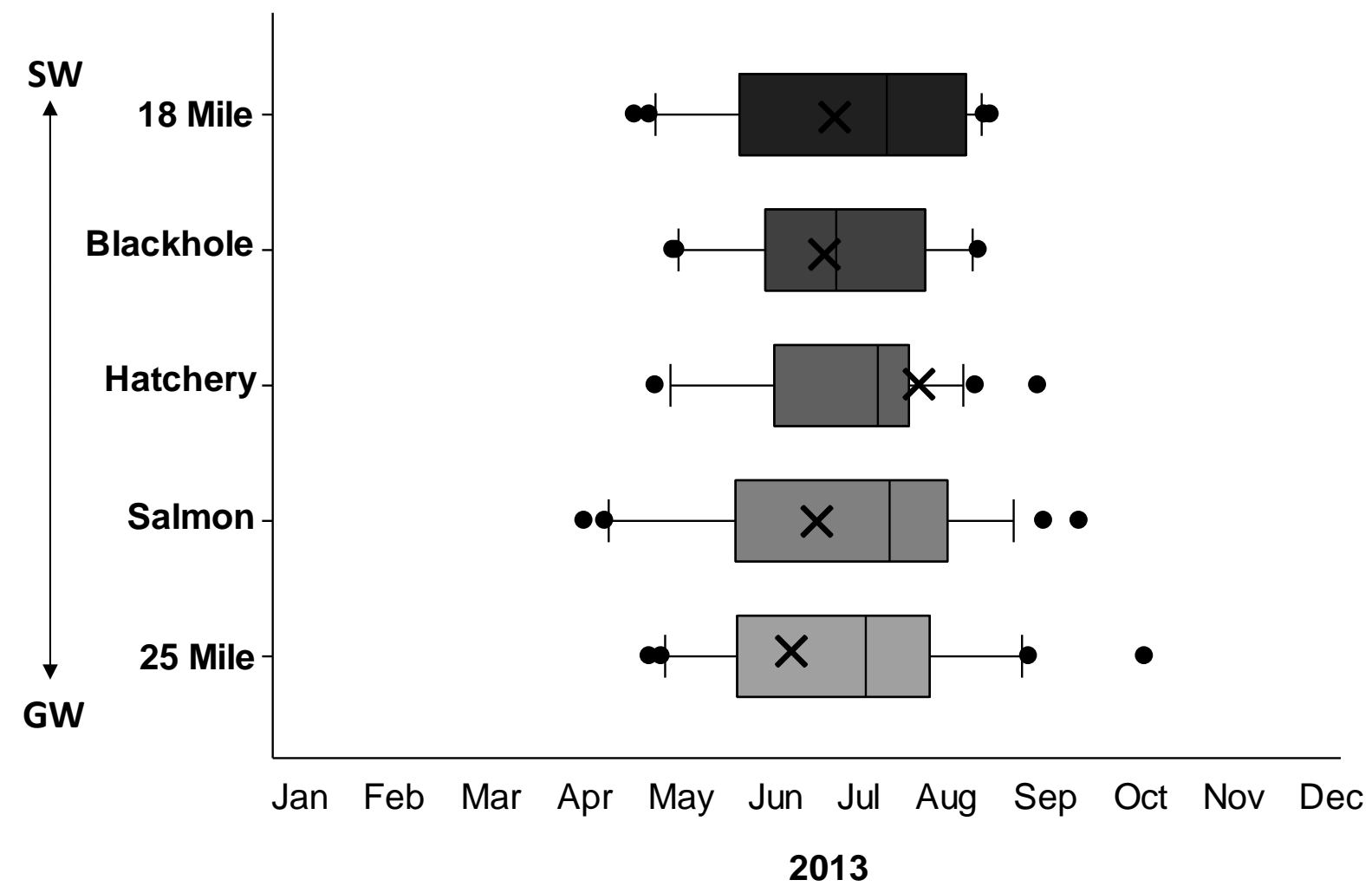

677

678

679

680

681

682

683

684

685

686 
Figure 5.

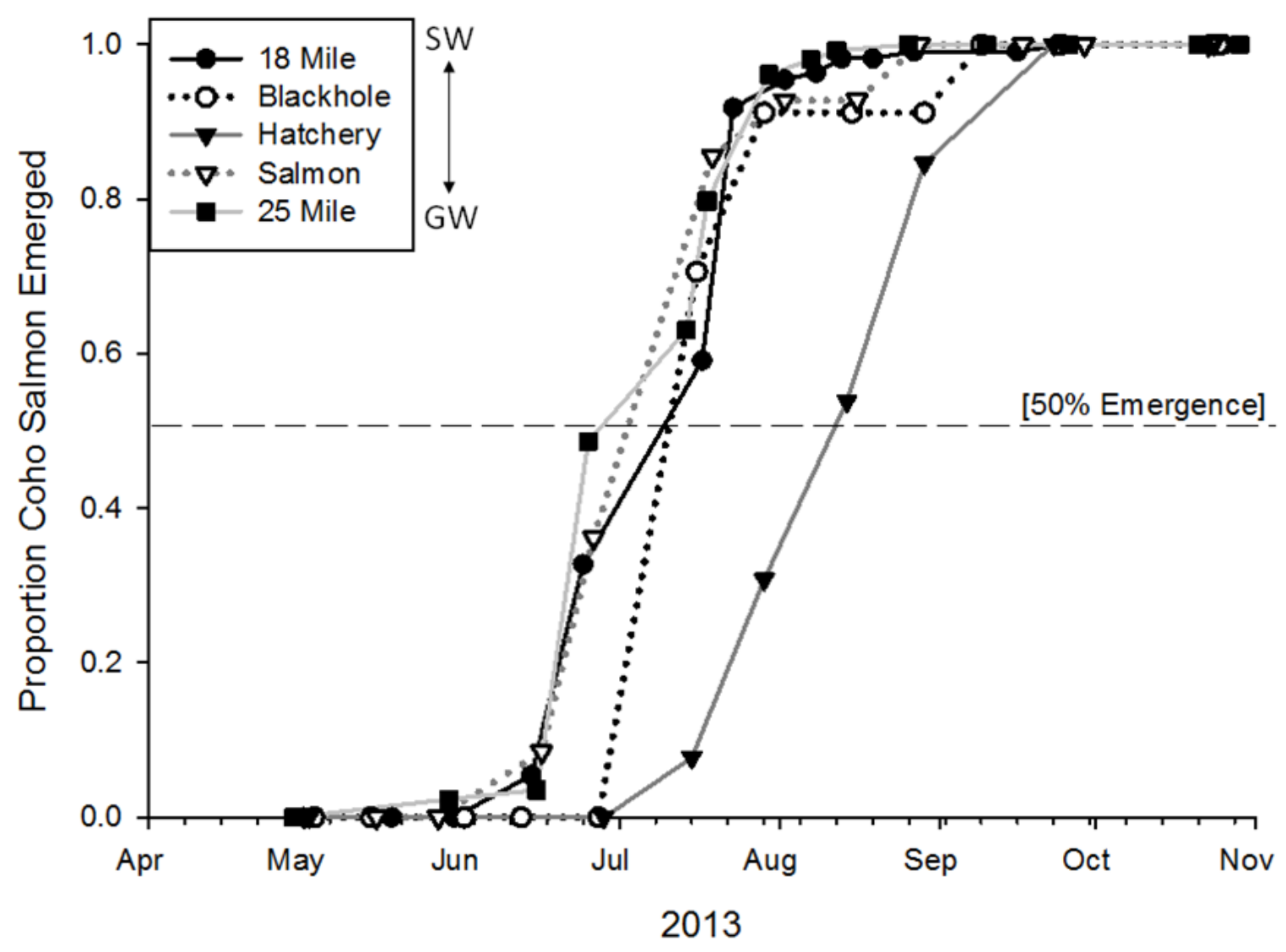

687

688

689

690

691

692

693

694

695 
Figure 6.

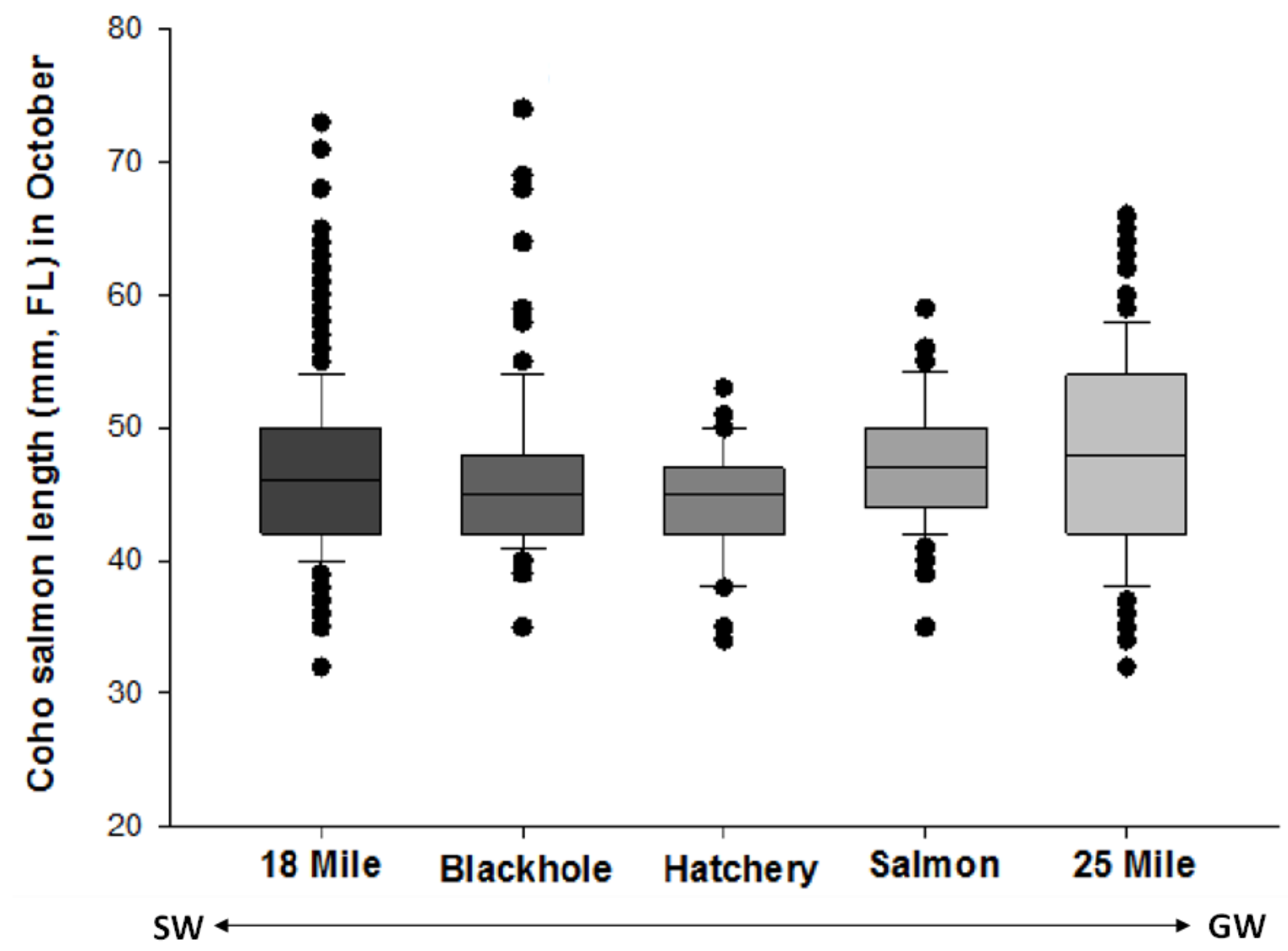

696

697

698

699

700

701

702

703

704 